INTERNATIONAL JOURNAL OF MULTIDISCIPLINARY RESEARCH AND ANALYSis

ISSN(print): 2643-9840, ISSN(online): 2643-9875

Volume 04 Issue 05 May 2021

DOI: 10.47191/ijmra/v4-i5-15, Impact Factor: 6.072

Page No.- 598-601

\title{
Formation of Reproductive Behavior of Student Youth in the Process of Studying the Humanities
}

\author{
Nigora Mamayusufovna Kenjaboeva \\ Doctor of Philosophy in Pedagogical Sciences (PhD), \\ Senior Lecturer, Department of "Methods of teaching languages" Regional Center for Retraining and Advanced Training of Public \\ Education Staff of Surkhandarya region
}

\begin{abstract}
This article addresses issues scientific analysis of state policy on the education of the reproductive culture of youth, the practical state of the development of the reproductive culture of students, scientific and pedagogical conditions for the development of the reproductive culture of students, information about the organization and conduct of the development of the reproductive culture of students.
\end{abstract}

KEYWORDS: Students, Reproductive, Reproductive Culture, Higher Education, Healthy Lifestyle.

\section{INTRODUCTION}

Research is being conducted to develop the medical-biological, socio-demographic, pedagogical-psychological content, forms and methods of formation of reproductive culture of youth in the world. The activities of international organizations such as the United States Agency for International Development (USAID), the Cairo International Conference (ARXA), UNICEF, UNFPA are aimed at studying the effective mechanisms for the development of reproductive culture. Issues such as reproductive health, demographic moderation, preparation for independent family life on the basis of a gender approach play an important role in the development of students' reproductive culture.

In our country, at all stages of the system of continuing education, systematic work is being done to promote a healthy lifestyle, strengthen the effectiveness of reproductive health of children and adolescents, increase the medical and pedagogical culture of the community, promote a healthy culture among the population.

Dear President Sh.M.Mirziyoyev: "Education of physically healthy, mentally and intellectually developed, independentminded, loyal to the Motherland, strong-minded outlook, support and realization of creative and intellectual potential of the younger generation, healthy life among children and youth One of our main tasks is to form the style of work, "he said.

Law of the Republic of Uzbekistan dated March 11, 2019 "On reproductive health", Decree of the President of the Republic of Uzbekistan dated February 7, 2017 "Strategy of actions on five priority areas of development of the Republic of Uzbekistan for 2017-2021" PF-4947, Cabinet of Ministers of the Republic of Uzbekistan 2018 Resolution No. 841 of October 20, 2006 "On measures to implement national goals and objectives in the field of sustainable development until 2030", as well as other normative legal acts related to this activity, this scientific article will serve to some extent.

\section{PURPOSE}

A healthy lifestyle of students is the basis for the formation of professional and pedagogical culture of future teachers. The healthy lifestyle of students is primarily based on a private healthy lifestyle, that is, the acquisition of personal knowledge in the field of health, the pursuit of a healthy lifestyle and the desire of a person to maintain their own health in their daily activities.

While highlighting the content of these areas, we focused on national values, traditions, in particular, the possibilities of higher education. On this issue, we have explained the content and essence of improving reproductive culture in young people by philosophers.

Speaking about the preparation of young people for life, O. Musurmanova believes that the main focus will be on the level of reproductive literacy of young people, as well as in this area, ie pedagogical aspects of preparation for family life, culture 


\section{Formation of Reproductive Behavior of Student Youth in the Process of Studying the Humanities}

of childbearing, "couple", "mother-child". the system of relations and dialogues, the use of national, universal values in this process.

In her research, D.Sharipova pays special attention to this area, protecting the health of a person who ignores the basics of personal hygiene, does not follow the rules of normal work, rest, sleep, does not pay attention to skin cleanliness, cloth ing, physical activity, harmful habits. emphasizes that it will not.

D.Khalikov's scientific researches studied sexual education, ethnopedagogical features of sexual education in Uzbek families as an object of research. D.Khalikov explains his opinion that "Only sex education can save the family and humanity."

In his research, S. Tursunov identified the development of a valeological approach to education through the pedagogical system "School of Health" in secondary special, vocational education institutions, the development of a healthy generation and the specific features, laws, principles and criteria for assessing the level of its development.

Student is a special group of specialties, which differs from everyone by always working in the same rhythm, intensively engaged in this type of mental work. Also, adaptation to the higher education process, high load and emotional stress during exams, various psychological and physiological stresses have a significant impact on their nervous and cardiac systems. This leads to the development of various neurological and cardiovascular diseases among students, as well as harmful habits in order to avoid stress.

The following factors also affect the healthy lifestyle of students: behavior, attitude to their health, maintaining and strengthening their health, timely access to medical care and a conscious approach to medical examinations, preventive measures.

According to the analysis of the scientific literature, the problems associated with the establishment of a healthy lifestyle among students have become more relevant in recent years. This is because, according to the analysis of student health and statistics, there is a gradual decline in health culture among students. This is due to a lack of knowledge about health, a healthy lifestyle, and a worldview worthy of it.

The health of students does not improve during their studies at the university, but worsens. For example, B.G. Akchurin proved that the incidence among pre-sophomore students is $23 \%$, while among pre-sophomore students this figure increases to $43 \%$.

From the first years of independence in our country, attention has been paid to the issues of deciding a healthy lifestyle among young people, preparing them for independent family life, strengthening reproductive health, combating drug addiction and AIDS among young people. Also, in order to form the necessary knowledge, skills and abilities in young people in these areas, the formation of a healthy lifestyle at all stages of higher education is organized through special programs.

Educational-methodical complexes for the development of students' reproductive culture are the main tool in acquiring the necessary knowledge and skills in this area.

Therefore, today a number of methodological manuals and programs have been created to help future primary school teachers to solve various social problems in everyday life, to make the right decisions about a healthy lifestyle. In particular, $\mathrm{O}$. Turaeva's "Family Ethics and Psychology" (1991), O. Musurmonova's "Family Spirituality - National Pride" (1999), G. Shoumarov's "1001 answers of a psychologist to 1001 questions" (2000), "Family Psychology" (2000) , M.Inomova's "Spiritual and moral education of children in the family" (1999), D.Sharipova and V.A.Tokareva's "Walk the path of youth without smoking", D.Sharipova's "Health is everyone's business", "And other similar literature is not only a valuable source of information for pedagogical psychologists of educational institutions, future primary school teachers, parents, but also serves as an important factor in the effective organization of the educational process. However, the literature does not provide sufficient information on the development of reproductive culture, in particular, the lack of attention to the development of reproductive health and reproductive culture due to the characteristics of the student period as a young age.

In this direction, not only students, but also parents, the creation of teaching aids, each educator-psychologist puts before the scientists an urgent task.

In the course of our observations and analyzes, medical-biological, pedagogical-psychological disciplines included in the curriculum of higher education institutions, such as "Youth Physiology and Hygiene", "Fundamentals of Valeology", "Social Pedagogy", "Family Psychology", "Social Psychology", "Family Pedagogy" We also got acquainted with the curricula of professional and specialized disciplines, such as

A total of 42 hours are allocated for the subject "Physiology and Hygiene of Youth" in the block of general disciplines, including 20 hours of lectures, 22 hours of laboratory classes. This subject is taught during the first stage, which teaches students the peculiarities of physiological growth and hygienic development. is intended to acquaint with. However, when we analyzed the curricula developed for science, the topics related to the development of reproductive culture were not considered. 


\section{Formation of Reproductive Behavior of Student Youth in the Process of Studying the Humanities}

Students are interested in studying the subject "Fundamentals of Valeology", which forms the knowledge, skills and abilities of students about a healthy lifestyle and its components. In all specialties of the bachelor's degree, the subject "Fundamentals of Valeology" is taught in the second stage on the basis of a total of 30 hours of workload (14 hours of lectures, 16 hours of seminars). When we get acquainted with the program, a series of information about human health we have witnessed themes. However, we have seen that topics aimed at developing reproductive culture are limited to "Reproductive Health and Disease" (4 hours: 2 hours of lectures, 2 hours of seminars).

Also, the problem of developing the reproductive culture of students is not fully reflected in the content of the disciplines "Psychology of Youth", "Social Pedagogy", "Social Psychology", which are taught as general subjects.

We are very satisfied with the information provided in the course "Family Psychology" on the social, psychological, physiological aspects of reproductive health and the conditions for the development of reproductive culture in young people, but given that this subject is taught as a pedagogical psychology, the dissemination of this information is limited.

D.K. Najmutdinova Study of the practical state of development of reproductive culture of students shows that there are the following shortcomings in this area.

Lack of favorable environment and pedagogical conditions for the development of reproductive culture of students in educational institutions.

1. Insufficient system of information, knowledge and skills on theoretical and practical issues of reproductive culture of students.

2. Insufficient coverage of topics aimed at the development of reproductive culture in the context of teaching medicalbiological, pedagogical-psychological sciences in higher education.

3. The narrowness of the scope of extracurricular activities aimed at developing the reproductive culture of students.

4. Lack of a methodological bank that provides information on reproductive health, healthy lifestyles and reproductive culture for young people in the student period.

5. Incomplete control over the development of students' reproductive culture by the teaching staff of higher education institutions.

We studied the pedagogical and psychological sources on the above shortcomings, analyzed the literature, studied the content of the curriculum in "Fundamentals of Valeology", "Youth Physiology and Hygiene", observed classes in these disciplines and provided students with knowledge, skills, trainings, interviews and surveys. were monitored on the basis of.

At this stage, taking into account the importance of improving a healthy lifestyle and reproductive culture in human life, questionnaires were recommended to future teachers to determine their views and level of knowledge.

362 respondents from the first and fourth stage students of the Tashkent State Pedagogical University named after Nizami, Termez State University and the Faculty of Pedagogy and Psychology of the Jizzakh Pedagogical Institute (direction of primary education methods) were involved in the survey. The questionnaire consisted of 30 questions and included inquiries on healthy lifestyle, sex education, preparation for marriage and family life, childbearing and parenting.

How would you describe the first "Healthy Lifestyle" concept in the survey? Participants in the question

$37 \%$ of students answered "Healthy lifestyle is good living, rest, health", $23.4 \%$ of students explained that this concept means to be healthy, not to give up bad habits (drinking, smoking), 21\% of participants said that healthy lifestyle - Regular participation in sports, adherence to the agenda for $10 \%$ of students, in some $(9 \%)$ is characterized by peace in the family.

"Are you always worried about your health?" 22.5\% of students answered "no", 16\% - "not always", 17.5\% "sometimes" and $44 \%$ of participants answered "yes".

"What do you mean by reproductive culture?" We were not satisfied with the answers given by the respondents to the question. This is because 80 per cent of first-year students and 73.4 per cent of third-year students surveyed could not correctly interpret the concept of reproductive culture.

"Do you think parents' health affects their children?" When asked, 90 percent of respondents said yes, but "Who is more responsible for having a healthy child; female or male? " $37 \%$ of the students responded that women were responsible (mostly boys), $38.4 \%$ both, and $24.5 \%$ men.

The data show that the acquisition of knowledge about reproductive culture is higher in girls than in boys.

Today, it is natural for women to take the lead in family life and sex. However, given that in Uzbek families, decisions about family relationships, family planning, and childbearing are made by men, it is problematic that young men are not fully aware of their knowledge of reproductive culture and healthy lifestyles. 


\section{Formation of Reproductive Behavior of Student Youth in the Process of Studying the Humanities}

The data show that students do not have enough ideas about a healthy lifestyle, reproductive culture. In our opinion, based on the information provided, it is advisable to implement the following measures aimed at developing the reproductive culture of students:

- Education of a responsible person who cares about their health on the basis of improving the spiritual and mental environment, strengthening the material and technical conditions in the higher education institution;

- to take into account the influence of regional and national-social scientists on the development of students' reproductive culture;

- Considering the importance of literacy not only of young people, but also parents and teachers in the formation of reproductive culture;

- Development of guidelines and brochures that provide information on the necessary conditions, content and essence of the development of reproductive culture;

- Extensive coverage of issues of reproductive health and a culture of healthy living in the context of medical-biological and pedagogical-psychological disciplines in the block of general professional sciences;

- redevelopment and implementation of the existing system of development of reproductive culture of students.

\section{CONCLUSION}

Preparing young people for independent family life, respect for family and marriage relations, improving reproductive culture are among the urgent issues that need to be addressed today. Because it is impossible to bring up a spiritually mature person, a qualified specialist, without forming a set of knowledge, skills and abilities aimed at ensuring a healthy lifestyle, worldview, social activity in young people.

We have focused on this aspect of the problem during our experiments, and today - in the development of the reproductive culture of students - we have come to the following conclusions.

1. In improving the reproductive culture of students, the content and essence of legal normative documents on the education and upbringing of students, scientific and theoretical ideas put forward in the field of pedagogy, psychology serve as a methodological basis.

2. Effective use of modern pedagogical technologies, interactive methods and information and communication technologies to improve the reproductive culture of future primary school teachers.

3. Designing, algorithmization, effective use of information and communication technologies, interactive methods of pedagogical process of improving the reproductive culture of future primary school teachers through socio-humanitarian and specialty subjects, special courses taught in higher education institutions. options have been identified.

4. In the context of the educational process and extracurricular activities, a broader coverage of healthy lifestyles, reproductive culture, sex education (even in non-specialty areas) and the use of non-traditional forms, methods and tools of educational activities play an important role.

If young people cannot protect their health, quality education, development, spiritual growth without harmful habits that harm their health, they will not be able to protect their health.

However, the education system is one of the important links that strengthen and shape a person's health. From this point of view, the fact that the knowledge and actions of students of higher education institutions are directed to this very purpose, first of all, shows that they should be equipped with the necessary knowledge and practical skills in this area.

\section{REFERENCES}

1) Mirziyoev Sh.M. We will build our great future with our brave and noble people. - T .: "Uzbekistan”, 2017. - 488 p.

2) Report on the situation of women in the Republic of Uzbekistan. Group of authors: Gulomova D., Saidova G., Kobulova D., Norboeva T and others. Published on the basis of the UNOPS project. - T .: 1999. - 96 p. Akchurin B.G. Spiritual and telesnaya organization of man. - Ufa: Izd-vo "Bashkir", un-ta, 2001. -257 p

3) Kenjaboeva N.M. About the culture of building a healthy family for young people. Risola. - T.: Sharq, 2009. - 40 p.

4) Kenjaboeva N.M. Formation of reproductive culture in student youth. Methodical manual.-T.: Mumtoz söz, 2011.-120p.

5) Sharipov A.D., Sharipova D., Tairova M. Kontseptualnbe osnovy formirovaniya ZOJ uchashchixsya. Education cherez vsyu jizn. St. Petersburg .: 2007. - 160 p.

6) Sharipova D.D. and dr. Metodicheskoe posobie dlya uchiteley po urokam zdorovya. UNICEF. 2006. - 256 p.

7) Musurmonova O. Family spirituality is a national pride. (Study guide). - T .: Teacher, 1999. - $200 \mathrm{p}$.

8) Najmutdinova D.K., Khasanova D.A. Reproductive health factors. Study guide. -T .: 2001. - 216 p. 